\title{
Gerhard Giebisch (1927-2020): a pioneer of kidney physiology
}

\author{
Heini Murer ${ }^{1} \cdot$ Carsten A. Wagner ${ }^{1}$
}

Published online: 1 June 2020

(C) Springer-Verlag GmbH Germany, part of Springer Nature 2020

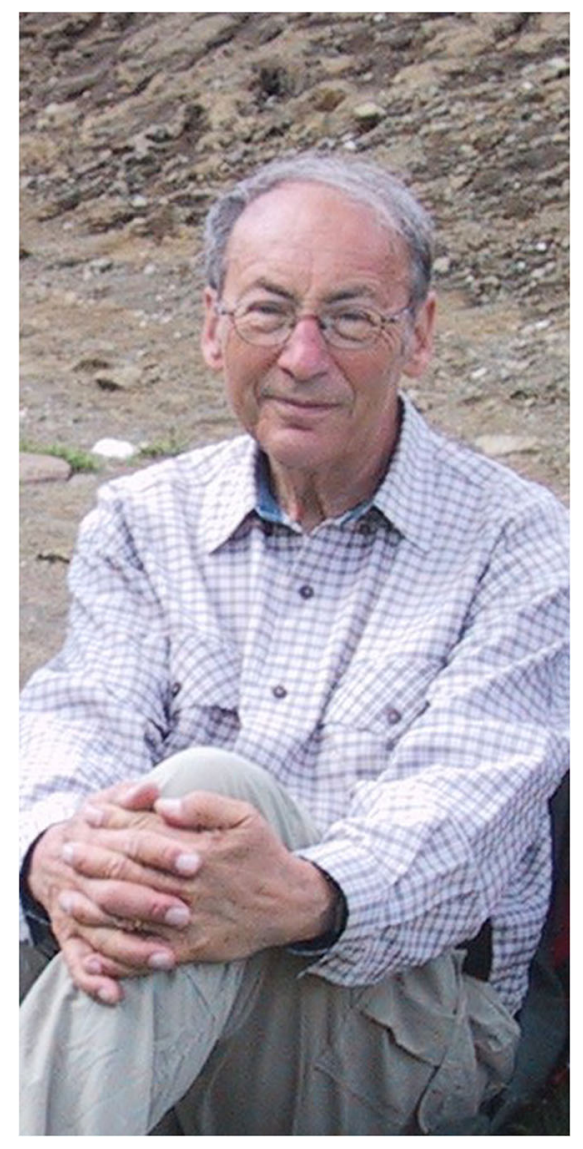

Gerhard Giebisch, picture taken in the Dolomites.

On April 6. 2020 Gerhard Giebisch passed away at the age of 93. He was one of the most influential kidney physiologists with his active career spanning more than 6 decades during which he established major concepts of renal functions that

HM and CAW published similar obituaries in J Am Soc Nephrol and NephroNews

Carsten A. Wagner

wagnerca@access.uzh.ch

1 Institute of Physiology, University of Zurich, Zurich, Switzerland have become textbook knowledge. He was a mentor and father figure for many transport and kidney researchers. He was the center of a worldwide network of former coworkers, colleagues, and friends, formed by discussions, collaborations, mutual interests beyond science, respect, and friendship.

Gerhard Giebisch was born 1927 in Vienna and he remained attached to his home city for all his life [1, 2]. His love for languages, literature and classic music, was sparked by his parents. He attended medical school in Vienna where his interest in (renal) physiology and pharmacology started inspired by reading Homer Smith's work and by spending one summer as a medical intern at the University Hospital Zurich under the direction of Otto Spühler. After gaining first research experience with Franz von Brücke at the Department of Pharmacology in Vienna, Gerhard moved to the United States in 1951 starting a clinical education which lasted only one year. After this short interlude, he joined the Department of Physiology at Cornell University Medical School headed by Robert Pitts. He trained in analytical and clearance methods focusing on acid-base and electrolyte transport related questions. By adding the micropuncture technique, he started exploring the amphibian Necturus tubule. He soon further developed these measurements by combining it with electrophysiological techniques paving the way for his later seminal studies. Integrating the then recent ideas on distinct basolateral and apical ion transport systems pioneered by Hans Ussing, he was among the first to describe segment specific driving forces and ion transport systems along the nephron. After a short return to Vienna, he was appointed as assistant professor at the Department of Physiology at Cornell in 1956. Here he met Erich Windhager and Gerhard Malnic both becoming life-long colleagues and close friends. With them Gerhard transferred the micropuncture technique from amphibian to mammalian nephrons and built an apparatus to measure ions in small nanoliter samples. These refinements and advances allowed them to explore important basic mechanisms of coupling between sodium transport and water movement in proximal and distal nephron segments. In the early 1960s Gerhard turned his attention to renal potassium handling, a topic that he would thoroughly investigate over the 
next four decades [3]. These studies from micropunctured and perfused nephron segments are the basis of our current textbook knowledge of tubular transport processes and particularly renal K-handling and its regulation.

In 1968 Gerhard Giebisch was appointed as the chair of the Department of Cellular and Molecular Physiology at Yale University and as the Sterling Professor of Physiology. In these functions he attracted many new members to the department and started again life-long collaborations with other researchers interested in kidney and epithelial physiology among them Emile Boulpaep, Peter Aronson, Michel Kashgarian, Joe Hoffmann, John Geibel, Richard Lifton, and many others. The vibrating research environment focused on epithelial transport processes was further supported by establishing a program project grant (led by Gerhard) bringing together many of the transport-interested researchers at Yale. The Department became a mecca for researchers interested in (epithelial) transport biology. During these years, Gerhard and his laboratory addressed many basic questions relating to tubular handling of $\mathrm{NaCl}$, water, acid-base equivalents, and importantly potassium, and their regulation. With the rise of cloning and molecular biology, Gerhard closely collaborated with Steve Hebert.

Gerhard Giebisch published over four hundred research articles. They are examples of clear argumentation avoiding any statement not supported by data. He received numerous awards including the Homer W. Smith award and the John P. Peters award of the American Society of Nephrology, the A. N. Richards award of the International Society of Nephrology, the Franz Volhard medal of the German Society of Nephrology, several honory doctorates, and was elected to the National Academy of Science. He served as President of both the American Society of Nephrology and the Society of General Physiologists.

Gerhards legacy goes far beyond his scientific achievements and the textbook "The Kidney" he edited together with his close friend Don Seldin. He trained and inspired several generations of young physiologists and nephrologists from all corners of the world. Many of them became established researchers in physiology or nephrology training new generations. Even many years after leaving his laboratory, he would still keep a vivid interest in them, their work, and offer his advice.
His research philosophy was driven by curiosity and the deep interest in understanding the kidney. He once jokingly remarked: "The kidney is the smartest organ, far more than the brain. It is able to adapt to various challenges. But do not tell this to the neurologists." In a review in 2011 [2] he reminded us to integrate molecular insights with the functional level of organs and the whole organism, a question central to his scientific reasoning and often asked in discussions with him.

Gerhard very much loved traveling. He was the center of large international network of colleagues, former fellows, and friends. He spent much time in Europe keeping close ties to his home city Vienna where he also frequently lectured. During summer, he would go to the Dolomites hiking and climbing with a small group of close friends. During the year he exercised diligently to be in shape for the mountains. In his office, he kept a large panorama picture of "his dolomites". His interests extended far beyond science and he very much loved the fine arts, particularly literature, classic music and opera. Gerhard was a good listener and always keen learning the latest news on science and politics and commenting them with a good sense of humor.

In 1952, he and his wife Ilse were married until her passing away in 2008. He remembered her "My late wife, Ilse, especially understood me and my somewhat relentless pursuit of research. It has been said, correctly I believe, that while I did research, she did everything else" [2]. He is survived by his two children, Christina Giebisch and Robert Giebisch and four grandchildren, Daniella and Marisa Mohrer and Allison and Daniel Giebisch.

\section{References}

1. Giebisch G (2008) APS living history of physiology archive. https:// www.youtube.com/watch?v=0PiuL51OA1Q\&feature=youtu.be

2. Giebisch GH (2011) A long affair with renal tubules. Annu Rev Physiol 73:1-28. https://doi.org/10.1146/annurev-physiol-012110142241

3. Stanton BA (2010) Renal potassium transport: the pioneering studies of Gerhard Giebisch. Am J Physiol Renal Physiol 298:F233-F234. https://doi.org/10.1152/ajprenal.00669.2009

Publisher's note Springer Nature remains neutral with regard to jurisdictional claims in published maps and institutional affiliations. 